Etnográfica

Revista do Centro em Rede de Investigação em

Antropologia

vol. $23(2) \mid 2019$

Vol. 23 (2)

\title{
Entre seres intangíveis e pessoas: uma introdução
}

Between intangible beings and persons: an introduction

\section{Emília Pietrafesa de Godoi e Marcelo Moura Mello}

\section{(2) OpenEdition \\ Journals}

\section{Edição electrónica}

URL: https://journals.openedition.org/etnografica/6837

DOI: 10.4000/etnografica.6837

ISSN: 2182-2891

\section{Editora}

Centro em Rede de Investigação em Antropologia

\section{Edição impressa}

Data de publição: 1 junho 2019

Paginação: 441-446

ISSN: 0873-6561

Refêrencia eletrónica

Emília Pietrafesa de Godoi e Marcelo Moura Mello, «Entre seres intangíveis e pessoas: uma introdução», Etnográfica [Online], vol. 23 (2) | 2019, posto online no dia 25 junho 2019, consultado o 20 janeiro 2022. URL: http://journals.openedition.org/etnografica/6837 ; DOI: https://doi.org/10.4000/ etnografica.6837

\section{(c) (i) 8)}

Etnográfica is licensed under a Creative Commons Attribution-NonCommercial 4.0 International License. 


\section{Entre seres intangíveis e pessoas: uma introdução}

\section{Emília Pietrafesa de Godoi}

\section{e Marcelo Moura Mello}

Este dossiê reúne artigos que abordam diversas ordens de intersecção e participação entre as vidas de humanos e seres como espíritos, exus, pombagiras, encantados, mortos, ancestrais, caboclos e vários outros. Os estudos aqui apresentados tratam da copresença e da participação destes seres no mundo social e de como essa copresença e essa participação são pensadas e vividas em distintos contextos etnografados. Ao trazer esses debates, o dossiê pretende somar-se a contribuições recentes, que, ao tratar destes seres, propõem pensar em novos termos questões relativas à história, à política, à materialidade, expandindo o campo dos estudos do ritual e da religião na antropologia.

PALAVRAS-CHAVE: seres intangíveis, pessoas, participação.

Between intangible beings and persons: an introduction - This special issue brings together articles that approach distinct orders of intersection and participation of the lives of humans and beings as spirits, eshus, pombagiras, encantados, dead, ancestors, caboclos, and many others. The articles here presented approach the co-presence and the participation of these beings in the social world, and how this co-presence and participation are thought and lived in different ethnographical contexts. Addressing these debates, the special issue aims to be an addition to recent studies that, in approaching these beings, propose to think in new terms questions related to history, to politics, to materiality, expanding the field of studies about ritual and religion in anthropology.

KEYWORDS: intangible beings, persons, participation.

GODOI, Emília Pietrafesa de (emilia.pietrafesa@gmail.com) - Universidade Estadual de Campinas, Brasil.

MELLO, Marcelo Moura (mmmello@gmail.com) - Universidade Federal da Bahia, Brasil. 


\section{ESTE DOSSIÊ RESULTA DE UM DIÁLOGO ANTROPOLÓGICO ENTRE} pesquisadores que colocaram a seus campos de pesquisa etnográfica questões concernentes à participação de seres intangíveis na vida das pessoas. Esse diálogo encontrou o seu lugar de forma mais sistemática no grupo de trabalho "Entre seres intangíveis e pessoas: experiência e história", coordenado por Emília Pietrafesa de Godoi e Marcelo Moura Mello no âmbito da 30. ${ }^{a}$ Reunião Brasileira de Antropologia. ${ }^{1}$ Os artigos aqui reunidos resultam das comunicações apresentadas e dos debates encetados naquele momento.

Quando falamos em participação de seres intangíveis na vida das pessoas, não há como não nos remetermos ao conceito lévy-bruhliano de "participação" (Lévy-Bruhl 1998 [1949]). Para o autor, a ideia de que as pessoas participam umas das outras "num processo de partibilidade constitutiva era o que explicava o pensamento mágico e estava na raiz dos próprios fenômenos identitários da vida pessoal e familiar" (Pina-Cabral e Godoi 2014: 14). Revisitando continuamente sua própria obra, Lévy-Bruhl reteve o senso de que participações eram indispensáveis à própria existência dos seres (Sahlins 2013), contribuindo decisivamente para as discussões em torno da noção de pessoa, questionando seja a suposta singularidade de indivíduos contidos em si mesmos (Pina-Cabral 2018), seja a partição entre o mundo dos vivos e o dos mortos (Mosko 2017).

Os resultados das pesquisas que ora se objetivam na forma dos artigos aqui apresentados nos levam a propor que não apenas as pessoas participam umas das outras, mas outros seres também; pois longe de estarem confinados a cosmologias, sistemas de ideias, representações e planos de existência cerrados, entes espirituais estão imersos no mundano e participam ritual e cotidianamente da vida dos humanos. E se, de um lado, suas características e seus atributos permitem antever os desdobramentos de suas ações, de outro, suas capacidades e potências são tão inesperadas quanto transgressivas, na medida em que seus atos e os efeitos de suas presenças atravessam fronteiras entre o ritual e o cotidiano, o sagrado e o mundano, o passado e o presente, o privado e o público. Seres intangíveis estão continuamente em movimento no tempo e no espaço, traçando caminhos e forjando (novas) relações, tanto no plano terreno quanto no espiritual.

Os artigos que compõem esse dossiê abordam diversas ordens de intersecção e participação entre as vidas de humanos e trajetórias de entes espirituais (espíritos, exus, pombagiras, encantados, mortos, ancestrais, caboclos, entre outros). Veremos de que modo a copresença e participação desses seres no mundo social é pensada e vivida em diversos espaços de experiência, lugares e momentos, nos distintos contextos etnografados. 
É sabido que entes espirituais ocuparam um lugar de destaque na produção antropológica desde os primórdios da disciplina, desde as teorizações de Tylor (1871) sobre o animismo até as monografias consagradas à ação de mortos no plano terreno, como o estudo pioneiro de Malinowski (1988 [1916]). Os modos pelos quais espíritos se tornaram passíveis de compreensão no quadro do regime de factualização da ciência variou ao longo do tempo, embora os enfoques consolidados tenham oscilado, via de regra, entre a sociologização e a psicologização dos espíritos, para que esses adquirissem um lugar entre os objetos científicos (Vasconcelos 2003). De igual modo, as reflexões em torno do entrelaçamento de entes espirituais às vidas de humanos circunscreveram-se a domínios especializados, como a antropologia da religião.

Não é nossa intenção, aqui, revisar a extensa produção bibliográfica em torno de entes espirituais ou sobre temáticas relativas, por exemplo, à possessão espiritual na antropologia (para panoramas mais detalhados, ver Boddy 1994; Engelke 2018; Lambek 1981), mas, antes, situar este dossiê à luz de desdobramentos teóricos e metodológicos recentes. Coletâneas como aquelas editadas por Blanes e Espírito Santo (2014), Espírito Santo e Tassi (2013) e Johnson (2014) não só congregam pesquisas etnográficas realizadas em várias partes do mundo como repensam criticamente os conceitos, tais como os de crença, normalmente empregados para se pensar entes espirituais. Não obstante as diferenças de enfoque e as filiações teóricas específicas a esse conjunto heteróclito de trabalhos, nota-se uma preocupação comum em expandir os enfoques centrados em cosmologias, em rituais e na religião, abarcando questões relativas à história, à materialidade, à política e à economia (Mello 2016; Godoi 2014).

Ao mesmo tempo, sem negar a importância de se descrever atentamente os contextos nos quais humanos e não humanos interagem, tais estudos sugerem que formas espirituais de existência não devem ser concebidas, meramente, como epifenômenos de configurações sociopolíticas ou históricas "mais reais". Assim, as trajetórias de entes espirituais no plano terreno se interseccionam com outros domínios particulares de experiência, como sonhos, visões, intuições, revelando muito sobre as histórias de vida de humanos. A copresença de seres intangíveis e humanos revela-se central, seja em narrativas e discursos, seja em corpos e na constituição de pessoas. Longe, portanto, de serem apartados, os domínios espiritual e mundano se interseccionam, gerando uma série de efeitos. Esses efeitos não são assumidos de antemão pelas contribuições aqui reunidas, mas se dão ao conhecimento etnograficamente, em diálogo com entendimentos locais de homens e mulheres em circunstâncias específicas.

Ao abordarem quatro histórias no artigo que abre este dossiê, "A família de Légua está toda na eira': tramas entre pessoas e encantados”, Martina Ahlert e Conceição de Maria Teixeira Lima pensam relações imersas em tramas familiares que apontam para os diversos agenciamentos constitutivos de pessoas e 
encantados no estado do Maranhão, no Brasil. O convívio entre essas personagens não se restringe a espaços específicos, tampouco limita-se ao âmbito privado, na medida em que encantados interagem com humanos em diversos domínios sociais (não só o religioso ou o ritual) e de experiência (como sonhos). Ademais, essas entidades envolvem-se tanto com as pessoas que as recebem como com seus parentes, vizinhos e amigos. Se, de um lado, essas relações promovem o compartilhamento de formas de cuidado e de companhia, de outro lado, são marcadas também por rupturas, quebras de vínculo, conflitos e afastamentos. Em diálogo com a literatura sobre religiões de matriz africana no Brasil e com aportes da antropologia a respeito de noções como pessoa e participação, as autoras demonstram como os caminhos que compõem uma pessoa e sua vida estão estritamente ligados a heranças relacionais precedentes, passíveis de serem transformadas com o desdobrar das relações entre encantados e humanos ao longo do tempo.

Já Márcia Nóbrega, no artigo "Variações sobre livusias: coincidência entre a terra e os (fim de) mundos contidos numa ilha no rio São Francisco, Brasil", analisa de que forma pessoas e espíritos ("almas" e "caboclos") convivem e povoam o espaço da Ilha do Massangano, situada no trecho submédio do rio São Francisco, no semiárido nordestino, entre os estados da Bahia e de Pernambuco, no Brasil. A tentativa da autora de compreender os processos por meio dos quais os espíritos, em suas múltiplas modulações, se fazem sentir, é particularmente atenta à pragmática dos efeitos de almas e caboclos, à coincidência de mundos em uma mesma terra. Nóbrega acompanha os habitantes do local, dando proeminência a conhecimentos que articulam a presença desses seres à força dos regimes das águas - cujas correntes foram afetadas pela construção de um complexo de barragens - e sua relação com a "terra firme", espreitada pela iminente morte do rio. Longe de propor imagens de fixidez, o artigo demonstra como o conhecimento se faz pelo caminhar, por deslocamentos, pelos movimentos e movimentações de mundos onde vivem pessoas e espíritos. Em suma, ao falar do mundo, os habitantes da Ilha do Massangano fazem afirmações de vida: de onde se vive, com que se vive, de como se vive e de como se caminha.

Em seu artigo "No-humanos que hacen la historia, el entorno y el cuerpo en el Chaco argentino", Florencia Tola analisa os efeitos de entidades não humanas (fenômenos atmosféricos, mortos, donos de animais, pássaros, etc.) entre os índios tobas (qom) do Chaco argentino, em três domínios analíticos. Primeiramente, a autora se debruça sobre os relatos indígenas acerca da conquista estatal de seus territórios no final do século XIX, nos quais entes não humanos incidiram no devir dos antigos qom, ocupando um papel central na maneira pela qual os indígenas modularam, relataram e viveram a passagem do tempo e sua historicidade. Em seguida, Tola sugere que o entorno dos qom, longe de ser um espaço neutro provedor de recursos naturais, apresenta determinadas 
características que são lidas como rastros deixados por seres não humanos. O corpo-pessoa dos tobas é um espaço socialmente transformado, cujo motor são outros acontecimentos nos quais diversas entidades intervêm, promovendo transformações. Por fim, a autora descreve diversas situações cotidianas atravessadas por vínculos e comunicações com animais, plantas e fenômenos atmosféricos. Para a autora, entes não humanos não se situam no âmbito metafórico, discursivo ou no plano mítico. A ontologia toba constitui uma forma de perceber, se relacionar e atuar em um mundo no qual diversos não humanos definem o corpo-pessoa, o entorno e a ação humana ao longo do tempo.

Privilegiando questões relativas à existência em si (ontologia), para além de questões de sentido, Moisés Lino e Silva, no artigo "Ontologia da confusão: Exu e o Diabo dançam o 'Samba do Crioulo Doido", analisa os modos pelos quais distintas formas de conhecimento influenciam a maneira como moradores da favela da Rocinha, na cidade do Rio de Janeiro, reconhecem, vivenciam e lidam com confusões em suas experiências diárias. Além de descrever confusões específicas em um ritual de umbanda, o autor argumenta que a existência de Exu - divindade associada, nas cosmologias de religiões afro-brasileiras, a acordos e desacordos, à ordem e à confusão - tem consequências diretas no entendimento da confusão no cotidiano da Rocinha, para além do domínio religioso. Lino e Silva apresenta um cenário ainda mais complexo ao abordar as considerações de evangélicos neopentecostais da Rocinha, que se recusam ostensivamente a celebrar confusões, fossem elas protagonizadas por humanos ou não humanos. Ao levar em conta a diversidade de considerações epistemológicas de diferentes moradores da favela, o autor agrega à sua análise as interseccionalidades entre religião, gênero e sexualidade, bem como as lutas e os conflitos de poder que asseguram ou negam a existência e o reconhecimento de confusões diversas.

Esse dossiê, assim apresentado, pretende constituir-se num estímulo ao diálogo e num convite ao leitor e à leitora para que teçam seus próprios arranjos das contribuições trazidas pelos artigos resultantes de estudos etnográficos em diferentes contextos sobre temas, desde cedo, muito caros à antropologia. 


\section{BIBLIOGRAFIA}

BLANES, Ruy, e Diana ESPÍRITO SANTO (orgs.), 2014, The Social Life of Spirits. Chicago, The University of Chicago Press.

BODDY, Janice, 1994, "Spirit possession revisited: beyond instrumentality", Annual Review of Anthropology, 23: 407-434.

ENGELKE, Matthew, 2018, "Spirit”, em Gaurav Desai e Adeline Masquelier (orgs.), Critical Terms for the Study of Africa. Chicago, The University of Chicago Press, 288-301.

ESPÍRITO SANTO, Diana, e Nico TASSI (orgs.), 2013, Making Spirits: Materiality and Transcendence in Contemporary Religions. Londres, I. B. Tauris.

GODOI, Emília Pietrafesa de, 2014, “Mobilidades, encantamentos e pertença: o mundo ainda está rogando, porque ainda não acabou”, Revista de Antropologia, 57 (2): 143-170.

JOHnSOn, Paul C. (org.), 2014, Spirited Things: The Work of Possession in Afro-Atlantic Religions. Chicago, The University of Chicago Press.

LAMBEK, Michael, 1981, Human Spirits: A Culture Account of Trance in Mayotte. Cambridge, Cambridge University Press.

LÉVY-BRUHL, Lucien, 1998 [1949], Les Carnets de Lucien Lévy-Bruhl, Paris, Presses Universitaires de France, org. Bruno Karsenti.

MALINOWSKI, Bronislaw, 1988 [1916], "Baloma: os espíritos dos mortos nas ilhas Trobriand”, em B. Malinowski, Magia, Ciência e Religião. Lisboa, Edições 70, 155-255.

MELLO, Marcelo Moura, 2016, "Entidades espirituais: materializações, histórias e os índices de suas presenças”, Etnográfica, 20 (1): 211 1-225.

MOSKO, Mark, 2017, Ways of Baloma: Rethinking Magic and Kinship from the Trobriands. Chicago, The University of Chicago Press.

PINA-CABRAL, João de, 2018, “Modes of participation”, Anthropological Theory, 18 (4): 435$-455$.

PINA-CABRAL, João de, e Emília Pietrafesa de GODOI, 2014, "Apresentação: vicinalidades e casas partíveis", Revista de Antropologia, 57 (2): 11 -21.

SAHLINS, Marshall, 2013, What Kinship Is and Is Not. Chicago, The University of Chicago Press.

TYLOR, Edward, 1871 , Primitive Culture. Londres, John Murray.

VASCONCELOS, João, 2003, "Espíritos clandestinos: espiritismo, pesquisa psíquica e antropologia da religião entre 1850 e 1920”, Religião e Sociedade, 23 (2): 92-126. 